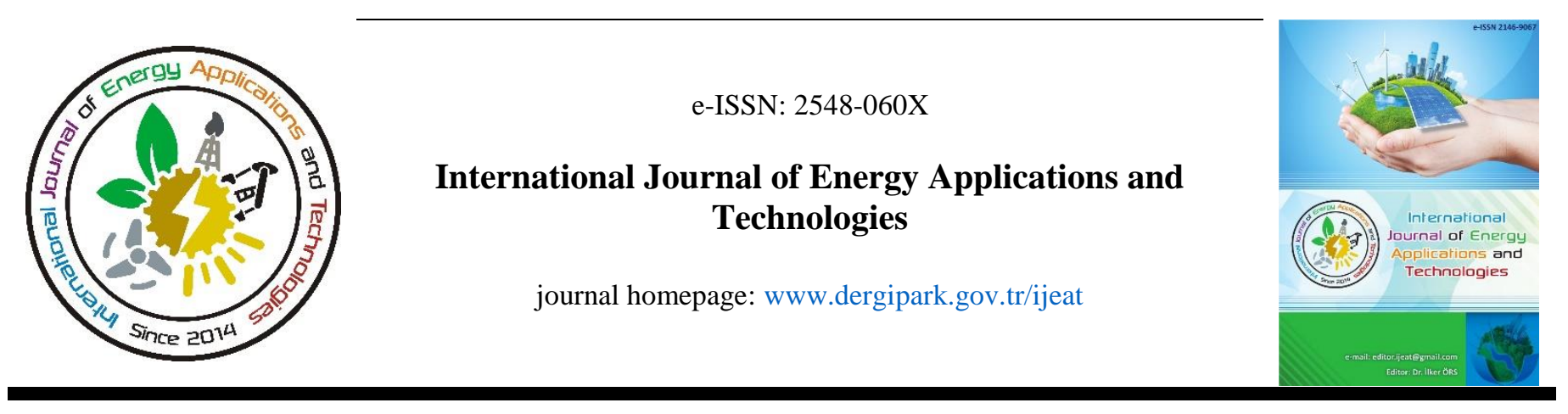

Original Research Article

\title{
Analysis of plate heat exchanger operating parameters by Taguchi Method
}

\author{
Ceyda Kocabaş*, Ahmet Fevzi Savaş \\ Bilecik Şeyh Edebali University, Bilecik,Turkey
}

\author{
ARTICLE INFO \\ * Corresponding author \\ ceyda.pak@bilecik.edu.tr \\ Received March 6, 2019 \\ Accepted December 24, 2019 \\ Published by Editorial Board \\ Members of IJEAT \\ (C) This article is distributed by \\ Turk Journal Park System under \\ the CC 4.0 terms and conditions. \\ doi: 10.31593/ijeat.536339
}

\begin{abstract}
In this study, the heat recovery performance of a plate heat exchanger, which provides air to air heat transfer was investigated. For the experimental set-up, a waste heat recovery device was designed and a heat exchanger was placed in it. Three different operating parameters were selected as fresh and exhaust air inlet temperatures and airflow rates. Three levels for each parameter were determined. The effects of changing parameters on the thermal effectiveness were analyzed by the Taguchi method. $\mathrm{L}_{9}\left(3^{3}\right)$ orthogonal array was used in performing experiments. Results indicate that higher effectiveness can be obtained at low fresh air inlet temperature, low airflow rate, and high exhaust air inlet temperature. In this way, the optimum process parameter combination was revealed. Then, ANOVA was applied in order to detect the significance order of each parameter. The results show that the most important parameter among the others is the airflow rate. Moreover, the confirmation test was performed in order to obtain the optimum parameter combination. The experimental and predicted values are compatible with each other. This experimental study approves that the Taguchi method can be used in improving the exchanger performance.
\end{abstract}

Keywords: Taguchi method; Plate heat exchanger; Cellulosic; Air to air heat recovery; Thermal effectiveness

\section{Introduction}

The rapid development of industrial applications leads to the depletion of natural resources. Day by day, tons of toxic gas is emitted into the atmosphere. Besides, greenhouse gas concentrations are increasing and they cause global warming. Therefore, Sustainability of energy resources has become a very important issue. Resources to be transferred to future generations should be protected as much as possible. With the energy savings to be made in industrial systems, it is possible to realize both environmentally friendly production and contribute to the economy of the country.

One of the ways to reduce energy consumption is heat recovery. Waste heat recovery is the process of recycling and reusing waste energy. This energy can be reused by means of equipment such as heat exchangers, heat pipes or waste heat boilers. Particularly, heat exchangers are one of the most preferred equipment of recovery of waste heat. They prevent heat from direct contact with the raw material and allow this heat to be used in many areas. For example; the high temperature polluted gases from an aluminum melting furnace can be used for heating the interior of the factory, hot water supply, preheating for the same or another process. Plate heat exchanger is one of the heat exchanger types used for heat recovery. Heat exchanger plates are generally made of a material having a high heat transfer coefficient. For this reason, metals are often preferred in plate production. However, particularly in humid and chemical environment, they are exposed to corrosive attack. Also when we used metals, only sensible heat can be transferred neglecting the 
latent heat because metals have less porosity to retain the moisture. For these reasons, companies turned to materials that could be alternative to metals. Nowadays, the heat exchanger made from vapor permeable membrane, such as processed paper or new microporous polymeric membrane, is capable of transferring both heat and moisture from one air stream to another, thereby providing total energy change [1]. Till date, a few research on the study of plate heat exchangers produced from paper or cellulose materials has been reported. Nasif et al. investigated the thermal performance of the enthalpy heat exchanger, which could provide heat and moisture transfer using kraft paper [2]. Kocabas and Savaş, compared the thermal performance of plate heat exchangers made from three different materials such as aluminum, polymer and cellulose in the waste heat recovery system [3]. Lee et al. discussed the operation of the total heat exchangers which is based on thin fibrous paper and tested performances of six exchangers made of different functional papers under different flow rates [4]. Zhang made comparisons of paperfin and paper-plate, and paper-fin and membrane-plate exchangers for heat and moisture recovery [5]. Liu et al. investigated the impact of two coating methods on enthalpy exchange efficiency of a cellulose fibre air-to-air heat /mass exchanger, through both theoretically and experimentally [6]. Using the Taguchi experimental design method, it can be determined how input factors affect system performance. Also, the optimum process parameter combination can be obtained. This method is widely used nowadays because it allows achieving the desired results with less experimentation, less time and less cost. Studies in which heat exchanger working performance is optimized by Taguchi method are available in the literature [7-12]. However, the application of this method based on energy recovery system is very few.

In this paper, different from the literature; factors affecting the waste heat recovery performance of a heat exchanger consisting of cellulosic plates were investigated by using Taguchi statistical experiment design method. This study aims to determine the best combination of the working parameters and to clarify the contribution rates of the factors statistically. Accordingly, variance analysis (ANOVA) was applied to determine the significance of the process parameters. Also, this test data will expand the air-to-air heat recovery database.

\section{Material and Methods}

The present experimental system simulates the process of transferring the heat contained in the exhaust air to the fresh air before the exhaust air is directed to the outer atmosphere. To simulate exhaust air; high-temperature air was obtained by using 4 lamella resistors $(500 \mathrm{~W})$. To simulate the fresh air, cold air was obtained by using the evaporator with a capacity of $886 \mathrm{~W}$. The exhaust and fresh air were set to different temperatures using temperature thermostats. Two fans with a speed of 2500/2700 rpm were used. One of these fans allows the exhaust air to be exhausted and the other to supply the fresh air to the interior. The effectiveness of the system was investigated by using different airflow rates. For this purpose, an anemometer was used to measure the flow rate of the air. The fan speed was adjusted and fixed at the desired value by using a one-phase speed controller [13].

Table 1. Uncertainty of measurement devices

\begin{tabular}{cccc}
\hline $\begin{array}{c}\text { Measurement } \\
\text { Device }\end{array}$ & Name & Range & Uncertainty \\
\hline Anemometer & Prova AVM-07 & $0-45 / \mathrm{m} / \mathrm{s}$ & $\pm 3 \%$ \\
Thermostat & Emko ESM-3710 & $(-40) /(+85)^{\circ} \mathrm{C}$ & $\pm 1 \%$ \\
Thermostat & Evko EVKB 21 & $(-50) /(+130){ }^{\circ} \mathrm{C}$ & $\pm 1 \%$ \\
\hline
\end{tabular}

The cross-flow plate heat exchanger is installed in the system to provide heat transfer between fresh and exhaust air. This system prevents dirty and clean air from mixing. The heat exchanger with a corrugated surface of $20 \times 20 \times 30 \mathrm{~cm}$ dimensions is shown in Figure 1.

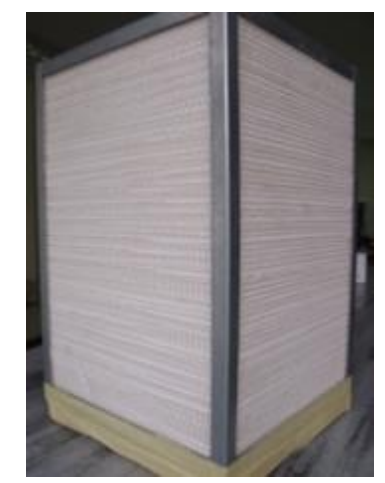

Fig. 1. Cellulosic heat exchanger.

The system operates as follows: When exhaust air is sent from one side of the plate, fresh air passes through the other side. To ensure this airflow, the fan is used. The heat flow is synchronized. During heat transfer, fresh air and exhaust air do not come into contact with each other. So, the only heat transfer takes place. When the system is operated in winter conditions; a warmer air is sent to the inside instead of cold fresh air. That is, by providing waste heat recovery; both increased thermal effectiveness and saved energy [13]. The schematic view of the system is shown in Figure 2.

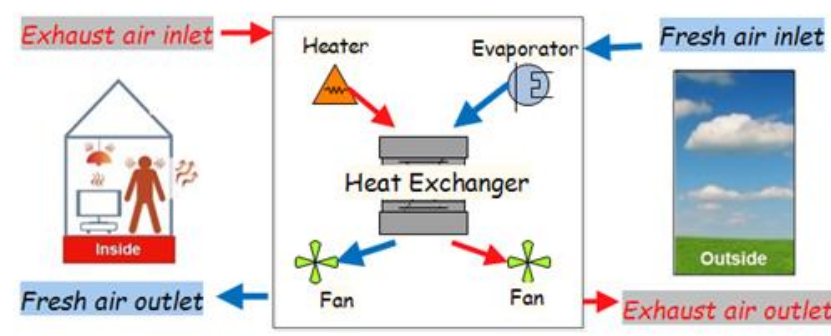

Fig. 2. Schematic diagram of the heat recovery system. 
Effectiveness analysis is one of the methods used to determine the thermal performance of the heat exchanger. The effectiveness $(\varepsilon)$ is the ratio of the actual heat transfer (Q) in a heat exchanger to the maximum possible heat transfer $\left(\mathrm{Q}_{\max }\right)$ and it is written as $\varepsilon=\mathrm{Q} / \mathrm{Q} \max$. The amount of actual heat transferred can be found from the heat given by the hot fluid or taken from the cold liquid as given below:

$$
\begin{aligned}
& Q=C_{h}\left(T_{h i}-T_{h o}\right) \text { or } Q=C_{c}\left(T_{c o}-T_{c i}\right) \\
& C_{h}=\dot{\mathrm{m}}_{h} C_{p h} \\
& C_{c}=\dot{\mathrm{m}}_{c} C_{p c} \\
& Q_{\max }=C_{\min }\left(T_{h i}-T_{c i}\right)
\end{aligned}
$$

The $Q_{\max }$ can be defined as the maximum amount of heat transfer that can be possible. This value can be found by selecting the smaller of the $\mathrm{C}_{\mathrm{h}}$ and $\mathrm{C}_{\mathrm{c}}$ and multiplying it with the difference between the inlet temperatures of the cold and hot fluids. With the help of the data obtained in the experimental study and using this correlation, the effectiveness values were determined.

In the experimental design method, the input factors are intentionally changed to detect changes in the output. It is observed that in which parameter combination the target output is obtained. This method is very useful for finding the best working conditions and predicting the individual effects of the factors. Experimental design is divided into two as factorial and fractional. If the number of parameters and levels are low enough, a full factorial design of the experiment is preferred. In contrast, the partial factorial design is used and only a part of the experiments is performed.

The Taguchi method is a type of partial factorial experimental design and uses orthogonal sequences. Taguchi offers a method that tries to reduce the variability in the process by selecting the levels of the factors that we can control against the factors that we cannot control. By determining the effects of the factors on the process output, it is possible to take caution against the factors that create variation during the process design phase. In the Taguchi approach, the signal-to-noise ratio $(\mathrm{S} / \mathrm{N})$ is used as a fundamental statistical criterion for evaluating system performance [11]. Signal (S); the actual value that is taken from the system and intended to be measured. Noise $(\mathrm{N})$; expresses the share of unwanted factors in the test result. The goal is to make the $\mathrm{S} / \mathrm{N}$ ratio the largest. [14]. Thus, while increasing the signal, on the one hand, we decrease the variance on the other hand. In our study, the goal is to maximize the heat exchanger effectiveness (efficiency). The required $\mathrm{S} / \mathrm{N}$ correlation is as the following equation. In the given equation $\mathrm{y}$ is the performance characteristic and $\mathrm{n}$ is the number of experiments performed.

To implement the Taguchi method, performance statistic, factors and their levels should be decided. Therefore, in current study; thermal effectiveness was chosen as performance characteristic and its maximization is targeted. Three factors have been determined as: air flow rate, fresh air inlet temperature and exhaust air inlet temperature. Three levels were selected for each factor. The factors represented by the letters $\mathrm{X}, \mathrm{Y}$ and $\mathrm{Z}$ are given in table 2 .

$$
S / N=-10 \log \left[\frac{1}{n} \sum_{i=1}^{n} \frac{1}{y_{i}^{2}}\right]
$$

Table 2. Factors and their levels

\begin{tabular}{ccccc}
\hline & Factors & $\begin{array}{c}1 . \\
\text { Level }\end{array}$ & $\begin{array}{c}2 . \\
\text { Level }\end{array}$ & $\begin{array}{c}3 . \\
\text { Level }\end{array}$ \\
\hline $\mathrm{X}$ & Fresh air inlet temperature $\left({ }^{\circ} \mathrm{C}\right)$ & 0 & 5 & 10 \\
$\mathrm{Y}$ & Air flow rate $(\mathrm{m} / \mathrm{s})$ & 1.2 & 1.6 & 2 \\
$\mathrm{Z}$ & Exhaust air inlet temperature $\left({ }^{\circ} \mathrm{C}\right)$ & 28 & 34 & 40 \\
\hline
\end{tabular}

In the Taguchi design, a ready orthogonal table suitable for the number of factors and levels can be selected. Using the orthogonal table, we can conduct experiments in a specific logic order. In full factorial design, we need to perform $3 \times 3 \times 3=27$ experiments to test all combinations of factors and levels since there are 3 factors and their 3 levels. Here we have chosen to use the experimental plan with $\mathrm{L}_{9}$ orthogonal sequence. Thus, the number of experiments required to be realized has decreased to 9 . The $\mathrm{L}_{9}$ (3-parameter and 3-level) orthogonal sequence used in this study is given in Table 3 . The numbers 1, 2 and 3 on each experiment line indicate the

\begin{tabular}{|c|c|c|c|c|c|}
\hline \multirow{2}{*}{$\begin{array}{c}\text { Exp. } \\
\text { No }\end{array}$} & \multicolumn{3}{|c|}{ Factors } & \multirow{2}{*}{ Effectiveness } & \multirow{2}{*}{$\mathrm{S} / \mathrm{N}$} \\
\hline & $\mathrm{X}$ & $\mathrm{Y}$ & $\mathrm{Z}$ & & \\
\hline 1 & 0 & 1.2 & 28 & 62.8 & 35.95 \\
\hline 2 & 0 & 1.6 & 34 & 62.7 & 35.94 \\
\hline 3 & 0 & 2 & 40 & 62.1 & 35.86 \\
\hline 4 & 5 & 1.2 & 34 & 63.4 & 36.04 \\
\hline 5 & 5 & 1.6 & 40 & 62.7 & 35.94 \\
\hline 6 & 5 & 2 & 28 & 60.1 & 35.57 \\
\hline 7 & 10 & 1.2 & 40 & 63.7 & 36.08 \\
\hline 8 & 10 & 1.6 & 28 & 60.7 & 35.66 \\
\hline 9 & 10 & 2 & 34 & 60.8 & 35.67 \\
\hline
\end{tabular}
levels of the factors.

Table 3. $\mathrm{L}_{9}\left(3^{3}\right)$ Orthogonal array

\begin{tabular}{cccc}
\hline $\begin{array}{c}\text { Experiment } \\
\text { No }\end{array}$ & $\begin{array}{c}\mathbf{X} \\
\text { Fresh air inlet } \\
\text { temp. }\left({ }^{\circ} \mathrm{C}\right)\end{array}$ & $\begin{array}{c}\mathbf{Y} \\
\text { Air flow } \\
\text { rate }(\mathrm{m} / \mathrm{s})\end{array}$ & $\begin{array}{c}\mathbf{Z} \\
\text { Exhaust air inlet } \\
\text { temp. }\left({ }^{\circ} \mathrm{C}\right)\end{array}$ \\
\hline 1 & 1 & 1 & 1 \\
2 & 1 & 2 & 2 \\
3 & 1 & 3 & 3 \\
4 & 2 & 1 & 2 \\
5 & 2 & 2 & 3 \\
6 & 2 & 3 & 1 \\
7 & 3 & 1 & 3 \\
8 & 3 & 2 & 1 \\
9 & 3 & 3 & 2 \\
\hline
\end{tabular}

Table 4. Effectiveness and $\mathrm{S} / \mathrm{N}$ ratios

According to the $\mathrm{L}_{9}$ experiment plan, 9 different experiments were performed using combinations of the selected factors at different levels. Each experiment was repeated twice and the averages were evaluated. The signal noise ratios of the results are given in Table 4. The calculation of $\mathrm{S} / \mathrm{N}$ ratios and 
graphical representation of the effects of the factors were performed by Minitab statistical software program. The S / N ratio helps to determine the effect of the parameters. The optimum values of the process parameters are always obtained at the levels with the highest $\mathrm{S} / \mathrm{N}$ ratios [9].

The effects of the factors are shown in Figure 3 and according to this graph;

- As the fresh air inlet temperature increases, the effectiveness decreases. The study of Niu and Zhang supports this conclusion. They investigated the effectiveness for different inlet air temperatures and found that latent effectiveness decreased with rising temperatures [16]. This is due to the decrease in the difference between the inlet and outlet temperatures. The recent studies support this statement [17, 18].

- As the air flow rate increases, the effectiveness decreases deeply. The study of Al- Waked et al. also supports this conclusion. They stated that the effectiveness of the heat exchanger decreases as the flow rate increases [15]. Niu and Zhang pointed that when the mass flux has increased the latent, sensible and also total enthalpy effectiveness decrease. They attributed this to the decline in NTU with the increasing mass flow rate [16]. Mardiana Idayu and Riffat noted that due to the amount of residence time within the heat recovery core, the effectiveness decreases with increasing velocity [19].

- The effectiveness increases as the exhaust air inlet temperature increases $[4,18]$. Because the sensible and latent effectiveness increases when the temperature difference between the temperature of the indoor and outdoor air increases [20].

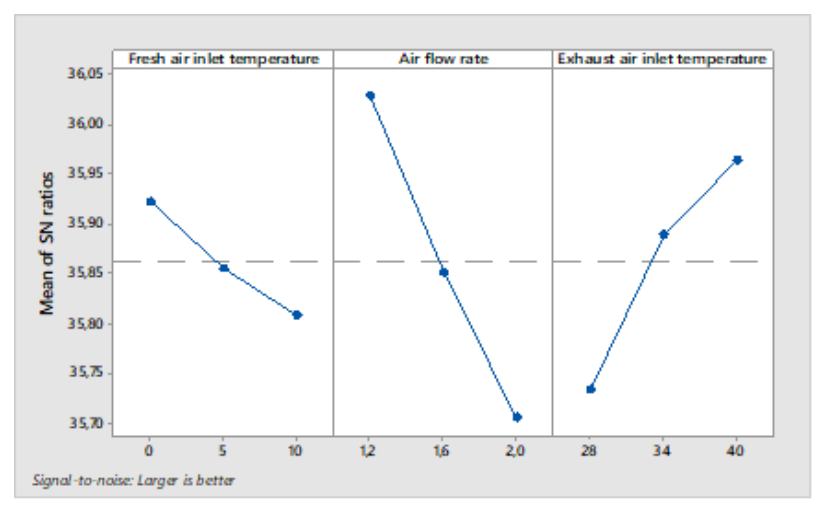

Fig. 3. The effects of process design parameters

Table 5. The mean of $\mathrm{S} / \mathrm{N}$ ratios

\begin{tabular}{ccccccccc}
\hline \multicolumn{2}{c}{ Fresh air inlet temperature } & \multicolumn{3}{c}{ Air flow rate } & \multicolumn{2}{c}{ Exhaust air inlet temperature } \\
\hline Level 1 & Level 2 & Level 3 & Level 1 & Level 2 & Level 3 & Level 1 & Level 2 & Level 3 \\
\hline 35.95 & 36.04 & 36.08 & 35.95 & 35.94 & 35.86 & 35.95 & 35.94 & 35.86 \\
35.94 & 35.94 & 35.66 & 36.04 & 35.94 & 35.57 & 35.57 & 36.04 & 35.94 \\
35.86 & 35.57 & 35.67 & 36.08 & 35.66 & 35.67 & 35.66 & 35.67 & 36.08 \\
$\mathbf{3 5 . 9 2}$ & $\mathbf{3 5 . 8 5}$ & $\mathbf{3 5 . 8 0}$ & $\mathbf{3 6 . 0 2}$ & $\mathbf{3 5 . 8 5}$ & $\mathbf{3 5 . 7 0}$ & $\mathbf{3 5 . 7 3}$ & $\mathbf{3 5 . 8 8}$ & $\mathbf{3 5 . 9 6}$ \\
& & & & & & Mean of S/N ratios & 35.857 \\
\hline
\end{tabular}

According to Figure 3, optimum parameters can be determined as $0{ }^{\circ} \mathrm{C}$ for the fresh air inlet temperature; $1.2 \mathrm{~m} / \mathrm{s}$ for airflow rate and $40^{\circ} \mathrm{C}$ for the exhaust air inlet temperature for existing working conditions. In order to make results significant and more reliable, the ANOVA method was implemented [21]. With ANOVA, it is easy to determine the degree of influence of the parameters on the process performance. $\mathrm{S} / \mathrm{N}$ ratios given in Table 4 were used in order to perform ANOVA. The mean of the $\mathrm{S} / \mathrm{N}$ ratios was taken separately for getting significance levels of factors. For instance, when the first level $(1.2 \mathrm{~m} / \mathrm{s})$ of the air inlet flow rate is selected, 1, 4 and 7 numbered experiments of Table 4 must be evaluated. In this way, the $\mathrm{S} / \mathrm{N}$ ratio average is determined as $(35.95+36.04+36.08) / 3=36.02$. The mean of the $\mathrm{S} / \mathrm{N}$ ratios of all factors calculated in this way has been given in Table 5. The total variance of the $\mathrm{S} / \mathrm{N}$ ratio needs to be calculated while implementing ANOVA. The following formulas are available for calculations [21, 22]:

$S S_{T}$ : Sum of the squares of total

$$
S S_{T}=\sum_{i=1}^{n}\left(\eta_{i}-\eta_{m}\right)^{2}
$$

$S S_{A}:$ Sum of the squares of factor $\mathrm{A}$

$$
S S_{A}=n_{A_{i}} \sum_{i=1}^{k_{A}}\left(\eta_{A_{i}}-\eta_{m}\right)^{2}
$$

$S S_{E}:$ Sum of squares of error

$$
S S_{E}=S S_{T}-\sum_{i=A}^{E} S S_{A}
$$

Contribution Ratio: $S S_{A} / S S_{T}$

$\eta_{i}=S / N$ ratio

$\eta_{m}=$ mean of $S / N$ ratios

$n=$ total number of experiments

$k_{A}=$ number of levels of factor $A$

$n_{A_{i}}=$ number of experiments at level $i$ of factor $A$

$\eta_{A_{i}}=S / N$ value at level $i$ of factor $A$

The ANOVA test results were given in Table 6. For instance; the sum of the squares for the factor Y (air flow rate) was determined as: 


$$
\begin{array}{r}
S S_{y}: 3 *\left[(36.02-35.857)^{2}+(35.85-35.857)^{2}\right. \\
\left.+(35.7-35.857)^{2}\right]=0.1573
\end{array}
$$

The contribution ratio means the effect of a factor on the performance characteristic and it can be found out dividing the sum of the square of this factor by the total. For example, contribution ratio for airflow rate (factor $\mathrm{Y}$ ) can be calculated as $0.1573 / 0.2618=0.60(60.1 \%)$. Contribution rates were calculated and the ranking according to these ratios was given in Table 6. The airflow rate is the most significant factor among other factors as it has a $60.1 \%$ contribution ratio. This is consistent with previous researchs. Niu and Zhang emphasized that the rates of air flows have a great impact on effectiveness [16]. Mardiana Idayu and Riffat expressed that air velocity has a significant effect on the effectiveness or efficiency of heat recovery [19]. They also noted that airflows have a significant effect on all types of heat recovery efficiency and recovered heat [1].

\begin{tabular}{|c|c|c|c|c|c|c|c|c|}
\hline & \multirow{2}{*}{$\begin{array}{l}\text { Degree of } \\
\text { freedom } \\
\text { (DF) }\end{array}$} & \multicolumn{3}{|c|}{ Average values } & \multirow{2}{*}{$\begin{array}{c}\text { Sum of } \\
\text { square } \\
\text { s (SS) }\end{array}$} & \multirow{2}{*}{$\begin{array}{c}\text { Sum of } \\
\text { mean } \\
\text { squares } \\
\text { (MS) }\end{array}$} & \multirow{2}{*}{$\begin{array}{l}\text { Contribution } \\
\text { rate } \%\end{array}$} & \multirow{2}{*}{ Ranking } \\
\hline & & Level 1 & Level 2 & Level 3 & & & & \\
\hline Fresh air inlet temperature & 2 & 35.92 & 35.85 & 35.8 & 0.0195 & 0.0097 & 7.4 & 3 \\
\hline Air flow rate & 2 & 36.02 & 35.85 & 35.7 & 0.1573 & 0.0786 & 60.1 & 1 \\
\hline $\begin{array}{l}\text { Exhaust air inlet } \\
\text { temperature }\end{array}$ & 2 & 35.73 & 35.88 & 35.96 & 0.0849 & 0.0424 & 32.4 & 2 \\
\hline Error & 2 & & & & 0.0002 & 0.0001 & 0.1 & \\
\hline Total & 8 & & & & 0.2618 & & 100 & \\
\hline
\end{tabular}

Table 6. ANOVA table

The secondary significant factor is the exhaust air inlet temperature with a ratio of $32.4 \%$. The fresh air inlet temperature has a minor effect on the result of the experiment (\%7.4). The study of Liu et al. supports this conclusion. They expressed that the sensible and latent effectiveness is not sensitive to the outdoor air temperature as long as there is no condensation and frost [23]. Yaici et al. specified that the outdoor temperature has only a minor effect on heat recovery [24].

Contribution ratios of all factors have been shown graphically in Fig.4. When we look at this figure, the significance order of factors can be seen more easily.

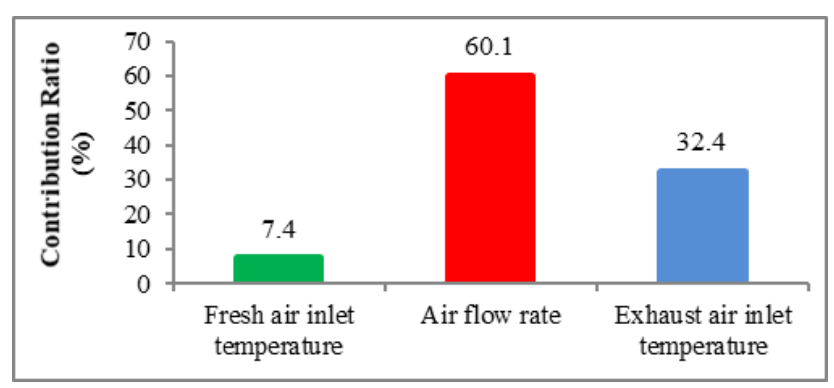

Fig. 4. Contribution ratios of factors

The confirmation test was performed on the optimum process parameters. The test sample was prepared for the optimal parameter combination $\left(\mathrm{X}_{1} \mathrm{Y}_{1} \mathrm{Z}_{3}\right)$. The confirmation test has been shown in Table 7. Confirmation tests were performed in 95\% significance level confidence (5\% error).

As shown in Table 7, the optimum effectiveness was expected as 64. 46. After the experiment, the actual value was obtained as 64.4. The actual and expected values are quite compatible with each other. In addition, the results show that the effectiveness of the optimal combination of process parameters provides better performance (64.4\%) than previous experiments. The confirmation results approve that the Taguchi approach can be implemented to improve the effectiveness of the heat exchanger used for heat recovery.

Table 7. Confirmation test

\begin{tabular}{lccc}
\hline \multicolumn{3}{c}{ Optimum Levels } \\
\hline Effective Factors & Level & Value & Average S/N \\
Fresh air inlet temperature & 1 & $0{ }^{\circ} \mathrm{C}$ & 35.92 \\
Air flow rate & 1 & $1.2 \mathrm{~m} / \mathrm{s}$ & 36.02 \\
Exhaust air inlet temperature & 3 & $40^{\circ} \mathrm{C}$ & 35.96 \\
Mean of S/N ratios & \multicolumn{3}{c}{35.857} \\
\hline & Expected & Actual \\
Expected S/N ratio & 36.19 & 36.18 \\
Optimum Effectiveness Value & 64.46 & 64.4 \\
\hline
\end{tabular}

As shown in Table 7, the optimum effectiveness was expected as 64. 46. After the experiment, the actual value was obtained as 64.4. The actual and expected values are quite compatible with each other. In addition, the results show that the effectiveness of the optimal combination of process parameters provides better performance (64.4\%) than previous experiments. The confirmation results approve that the Taguchi approach can be implemented to improve the effectiveness of the heat exchanger used for heat recovery.

\section{Conclusions}

In this article, changes in the heat recovery performance of the heat exchanger under different operating conditions have been investigated experimentally. A device was designed and constructed to simulate air to air waste heat recovery. For this purpose, a cross-flow plate heat exchanger made of cellulosic material was placed into the system. Three different process parameters were selected as fresh air inlet temperature, the airflow rate, and the exhaust air inlet temperature. Three levels were determined for each parameter. Thermal effectiveness $\varepsilon$ was used as the performance characteristic. 
The influence of three operating parameters on the thermal effectiveness was analyzed by the Taguchi method. The experiments were performed following Taguchi's $\mathrm{L}_{9}$ orthogonal array. The parameters were analyzed by using the $\mathrm{S} / \mathrm{N}$ ratios and ANOVA. Minitab statistical software program was preferred in the analysis. Results indicate that better effectiveness was achieved at a low airflow rate, low fresh air inlet temperature, and high exhaust air inlet temperature. Based on the ANOVA results, it can be concluded that all parameters have a significant effect on the performance characteristics. The airflow rate has been determined as the most significant parameter on thermal effectiveness. The exhaust air inlet temperature is at second order and the fresh air inlet temperature is third. Parameter combination that allows maximum heat transfer has been described as $\mathrm{X}_{1}, \mathrm{Y}_{1}$, $Z_{3}$. Compared to the other tests, the highest thermal effectiveness $(64.4 \%)$ was obtained when this combination was tried. It can be seen from the confirmation test that expected values are quite compatible with the actual ones. In this respect, the Taguchi approach can be used easily in analyzing and optimizing the heat exchanger thermal performance.

\begin{tabular}{|ll|}
\hline \multicolumn{2}{|l|}{ Subscripts } \\
$\mathrm{c}$ & cold air \\
$\mathrm{C}_{\mathrm{c}}$ & heat capacity of the cold air \\
$\mathrm{C}_{\mathrm{h}}$ & heat capacity of the hot air \\
$\mathrm{c}_{\mathrm{i}}$ & cold air inlet \\
$\mathrm{c}_{\mathrm{o}}$ & cold air outlet \\
$\mathrm{C}_{\mathrm{pc}}$ & specific heat of the cold air \\
$\mathrm{C}_{\mathrm{ph}}$ & specific heat of the hot air \\
$\mathrm{h}$ & hot air \\
$\mathrm{h}_{\mathrm{i}}$ & hot air inlet \\
$\mathrm{h}_{\mathrm{o}}$ & hot air outlet \\
$\dot{\mathrm{m}}$ & mass flow \\
\hline
\end{tabular}

\section{References}

[1] A. Mardiana and S. B. Riffat, "Review on physical and performance parameters of heat recovery systems for building applications", Renewable and Sustainable Energy Reviews, vol. 28, pp. 174-190, 2013.

[2] M. S. Nasif, R. Al-Waked, M. Behnia, M. and G. Morrison, "Modeling of air to air enthalpy heat exchanger," Heat Transfer Engineering, vol. 33, pp. 1010-1023, 2012.

[3] C. Kocabaş and A.F. Savaş, "Comparison of waste heat recovery performances of plate-fin heat exchangers produced from different materials," Contemporary Engineering Sciences, vol. 8(11), pp. 453 -466, 2015.

[4] Y. Lee, M. Jeng C. Huang, J. Perng, and C. Lan, "Analysis of cross-flow type of air-to-air total heat exchangers made of functional paper", International Journal of HVAC \& Research, vol. 11 (2005), 395-410.

[5] L. Zhang, Heat and mass transfer in plate-fin enthalpy exchangers with different plate and fin materials. International Journal of Heat and Mass Transfer, 52 (2009), 2704-2713.

[6] S. Liu, S. Riffat, X. Zhao, Y. Yuan, “ Impact of adsorbent finishing and absorbent filming on energy Exchange efficiency of an air-to-air cellulose fibre heat \& mass exchanger", Building and Environment, vol. 44, pp. 1803-1809, 2009.

[7] Junqi D., Yi Z., Gengtian L., Weiwu X., "Experimental study of wavy fin aluminum plate fin heat exchanger", Experimental Heat Transfer, 26, 384-396 (2013).

[8] Zhao-gang Qi, Jiang-ping Chen, Zhi-jiu Chen, "Parametric study on the performance of a heat exchanger with corrugated louvered fins", Applied Thermal Engineering, 27: 539-544 (2007).

[9] Turgut E.,Çakmak G., Yıldız C., "Optimization of the concentric heat exchanger with injector turbulators by Taguchi method", Energy Conversion and Management, 53, 268-275 (2012).

[10] Bayram Şahin and Alparslan Demir, "Thermal performance analysis and optimum design parameters of heat exchanger having perforated pin fins", Applied Energy Conversion and Management, 49: 1684-1695 (2008).

[11] Tingting Du, Wenjing Du, Kai Che, Lin Cheng, "Parametric optimization of overlapped helical baffled heat exchangers by Taguchi method", Applied Thermal Engineering, 85, 334-339 (2015).

[12] Isak Kotcioglu, Ahmet Cansiz and Mansour Nasiri Khalaji, "Experimental investigation for optimization of design parameters in a rectangular duct with platefins heat exchanger by Taguchi method", Applied Thermal Engineering, 50, 604-613 (2013).

[13] C. Kocabaş and A.F. Savaş,. "Analysis of Heat Exchanger Performance by Experimental Design Method", Afyon Kocatepe University Journal of Science and Engineering, 18, 1174-1180, 2018.

[14] Özçelik B. Ve Özbay A., "Determinatıon of Effect on the Mechanical Properties of Polypropylene Product of Moldıng Materıals Using Taguchi Method", Journal of Engineering and Natural Sciences Sigma 29, 289-300, 2011.

[15] R. Al-Waked, M. Ş. Nasif, G. Morrison, M. Behnia, "CFD simulation of air to air enthalpy heat exchanger", Energy Conversion and Management, 74, 377-385, 2013.

[16] J.L. Niu, L.Z. Zhang, "Membrane-based Enthalpy Exchanger: material considerations and clarification of 
moisture resistance", Journal of Membrane Science, 189, 179-191, 2001.

[17] Koyuncu T., "Design and construction of cross flow plate and finned type heat exchangers for ventilation", $\mathrm{Ph}$. D. Thesis, Trakya University, Institute of Science and Technology, Tekirdağ, 80, 1998.

[18] C. Kocabaş, A. F. Savaş, "Heat recovery optimization", International Conference on Engineering Technologies, October 26-28, 2018, Konya, Turkey.

[19] A. Mardiana-Idayua, Saffa B. Riffat, "An experimental study on the performance of enthalpy recovery system for building applications", Energy and Buildings, 43, 2533-2538, 2011.

[20] V.Yu. Borodulin, M.I. Nizovtsev, "A criterial analysis of the effectiveness of air-to-air heat exchangers with periodic change of airflow direction", Applied Thermal Engineering vol. 130, pp. 1246-1255, 2018.

[21] T. Du, W. Du, K. Che, Lin Cheng, "Parametric optimization of overlapped helical baffled heat exchangers by Taguchi method", Applied Thermal Engineering, vol. 85, pp. 334-339, 2015.

[22] M. Savaşkan, Y. Taptık., M. Ürgen, "Performance optimization of drill bits using design of experiments" [In Turkish],, İtu Article, Engineering, vol. 3(6), pp. 117-128, 2004.

[23] P. Liu, M. J. Alonso, H. M. Mathisena, C. Simonson, "Performance of a quasi-counter-flow air-to-air membrane energy exchanger in cold climates", Energy and Buildings, vol. 119, pp. 129-142, 2016.

[24] Yaïci W., Ghorab M. Entchev E., "Numerical analysis of heat and energy recovery ventilators performance based on CFD for detailed design", Applied Thermal Engineering, vol. 51, pp. 770-780, 2013. 